\title{
Derrida e o problema da linguagem matemática: suplementos à fenomenologia de Husserl
}

\author{
Derrida and the problem of mathematical lansuase: \\ supplements to Husserl's phenomenology
}

\author{
Vitor Araújo \\ Doutorando do programa \\ de pós-graduação em filosofia \\ da Pontifícia Universidade \\ Católica do Rio Grande \\ do Sul \\ araujovitor87@gmail.com
}

Recebido em 08/11/2017

Aceito em 13/03/2018

\begin{abstract}
Resumo
O presente texto tem o objetivo de apresentar a linguagem matemática em Husserl e em seguida indicar algumas das objeções e suplementações de Derrida ao texto do fenomenólogo. A abordagem de Derrida sobre o problema da matemática se dá através das mediações husserlianas acerca da insuficiência da pura sintaxe e na aposta de uma ciência capaz de explicitar o sentido fundamental dos números. Derrida, na longa apresentação à Origem da geometria se situa muito próximo do último texto de Husserl, procurando explicitar conceitos fundamentais e diferenciar a filosofia fenomenológica das tradições metafísicas e da filosofia crítica. Entretanto, a apresentação de Derrida não pode realizar apenas uma exposição de Husserl sem subverter a letra do filósofo alemão. O texto se depara constantemente com uma redução fenomenológica incapaz de produzir a unidade do eu transcendental. $\mathrm{O}$ fantasma da linguagem e da vida comum seriam dois pontos de irredutibilidade ao projeto de Husserl a partir do qual o transcendental deveria ser pensado não como a unidade pacífica do Eu, mas como Diferença.
\end{abstract}

Palavras-chave: Matemática; Fenomenologia; Derrida; Husserl.

\section{Abstract}

The present text has the objective to present the mathematical language in Husserl and then to indicate some of the objections and supplements of Derrida to the text of the phenomenologist. Derrida's approach to the problem of mathematics occurs through Husserlian mediations about the insufficiency of pure syntax and the bet of a science capable of explaining the fundamental meaning of numbers. Derrida, in the long presentation to the Origin of geometry, is very close to the last text of Husserl, trying to explain fundamental concepts and to differentiate the phenomenological philosophy from the metaphysical traditions and the critical philosophy. However, Derrida's presentation can only perform an exposition of Husserl subverting the letter of the German philosopher. The text is constantly faced with a phenomenological reduction incapable of producing the unity of the transcendental self. The phantom of language and ordinary life would be two points of irreducibility to Husserl's project from which the transcendental should be thought not as the peaceful unity of the Self, but as Difference.

Keywords: Mathematics; Phenomenology; Derrida; Husserl. 
A abordagem de Derrida sobre o problema da matemática se dá através das mediações husserlianas acerca da insuficiência da pura sintaxe e na aposta de uma ciência capaz de explicitar o sentido fundamental dos números. Husserl, a partir de uma investida racionalista, procura investigar o caráter primevo dos números, suas unidades originárias, e, assim, derivar destas unidades as aparições das multiplicidades encontradas nas equações matemáticas. O psicologismo que o fenomenólogo precisou pressupor como a condição do sentido dos números, no entanto, teve de ser superado e Husserl viu na filosofia transcendental e na distinção entre o eu sujeito e o eu objeto (mais especificamente nos paralogismos da razão pura) a possibilidade de um sentido que não fosse derivado de leis psicológicas. Após passar de uma fenomenológica estática para um nível mais profundo de aclaramento dos níveis primitivos dos conceitos, Husserl parece colocar a matemática em um lugar menos importante, talvez até dispensável, para pensar a historicidade (Geschichtlichkeit) do eu transcendental. Todavia, em suas últimas publicações, mais detalhadamente no seu livro A crise das ciências europeias e a fenomenologia transcendental, Husserl se reaproxima da matemática e constrói um percurso teleológico sem abrir mão do formalismo. Deste modo, o formalismo deve ser parte de uma trama na qual a ordenação dos conceitos e dos nomes próprios são, na verdade, um caminho necessário para o aclaramento das condições epistêmicas que finaliza sua caminhada na compreensão de si mesma na filosofia fenomenológica.

Derrida, na longa apresentação à Origem da geometria se situa muito próximo do último texto de Husserl, procurando explicitar conceitos fundamentais e diferenciar a filosofia fenomenológica do que o filósofo francês denomina como tradições metafísicas (Hegel) e como filosofia crítica (Kant). Entretanto, a apresentação de Derrida não pode realizar apenas uma exposição de Husserl sem subverter a letra do filósofo alemão. $\mathrm{O}$ texto se depara constantemente com uma redução fenomenológica incapaz de produzir a unidade do eu transcendental. $\mathrm{O}$ fantasma da linguagem e da vida comum seriam dois pontos de irredutibilidade ao projeto de Husserl a partir do qual o transcendental deveria ser pensado não como a unidade pacífica do $\mathrm{Eu}$, mas como Diferença.

O presente texto tem o objetivo, portanto, de apresentar a linguagem matemática em Husserl e em seguida indicar as objeções e suplementações de Derrida ao texto do fenomenólogo. A exposição procura contrapor dois modos de leitura da filosofia husserliana: de um lado, o transcendental como a garantia da síntese das multiplicidades (tradição) e de outro o transcendental como o risco do fracasso desta síntese (a crítica da tradição).

\section{Husserl e o sentido da matemática}

Desde o início de seus trabalhos sobre o objeto matemático, Husserl tinha uma importante finalidade, qual seja, a de produzir as condições de surgimento do formalismo, apostando que a resposta para esta questão residia na acessibilidade do significado do número. Por este motivo, a investigação da noção de número estaria subjacente ao sentido da contagem, que tinha como resultado uma multiplicidade de unidades. A linguagem matemática, para Husserl, representava o meio de acesso a um sentido universal e, portanto, os signos usados na operação matemática não poderiam ser entendidos como puras multiplicidades, como se se tratassem de formas não ordenadas de uma sintaxe sem sujeito ou finalidade. A unidade ideal almejada por Husserl, a princípio, seria enormemente alimentada por um psicologismo para escapar das formas cegas do formalismo, uma vez que o sujeito produtor das operações matemáticas carrega a possibilidade de iluminação do significado de uma operação desde que disposto a refletir sobre sua unidade. Por exemplo, no caso da contagem, a nomenclatura que sintetiza a multiplicidade dos números cardinais: o dois, o três, o quatro e assim por diante, nada mais é do que a adição sintética de uma operação infinita (um e um e um e um, etc). Para Husserl (1994),

Sinais e relacionamentos sem sentido entre sinais - de que uso deveriam ser para nós? Que uma classe de representações gerais e os julgamentos relacionados permitam certos métodos sistemáticos de dedução que podem ser compreendidos em regras uniformes só isso parece justificar a possibilidade de elaborar mecanismos de cálculo por meio de 
uma simbolização paralela. Um segue os sinais e suas regras, e, portanto, poupa e substitui o pensamento e as regras do pensamento. Mas parece absurdo que os sinais que não designam nada, aqueles que existam sem qualquer sentido interpretável, sejam capazes de realizar algo (p. 15, grifos nossos) $)^{1}$.

Husserl acreditava ser possível encontrar, subjacente ao sentido das operações matemáticas, uma significação elementar dos números mediante a decomposição da imediatidade dos procedimentos da ciência numérica. Em poucas palavras, "números não são apenas sinais, números têm significado" (KUSCH, 2001, p.39). Os casos apresentados por Husserl (1994) são muitos. Por exemplo, ele nos fornece a simplicidade dos casos dos números cardinais, propondo um fundacionismo aritmético, deduzindo o sentido do número 3 a partir da simples operação entre duas unidades mais simples $(2(1+1)+1)$. Assim, o número 3 nada mais é do que a somatória algébrica da operação $2+1$. O fundacionismo husserliano procura, portanto, chegar até a unidade simples dos números, na qual as operações aconteceriam sem a devida compreensão do sentido que subjaz às equações e que são dependentes delas. A presença de um conjunto de números não é apenas, para Husserl, a presença de unidades decomponíveis em unidades simples, mas também a relação que estas unidades possuem com a totalidade do sentido atribuído à equação (CENTRONE, 2010)².

A existência de um fundamento em comum parece ser o norte do primeiro trabalho de Husserl (2003) no qual há uma tentativa de depreender da multiplicidade do objeto matemático as suas unidades constitutivas a partir de um método distinto daquele do formalismo cuja premissa seria a de que os números seriam apenas signos vazios. Para atingir esse resultado, Husserl revive uma tradição ortodoxa de encerrar o signo nos limites de um sujeito psicológico, na qual todas as representações de números bem como as formas da sucessão temporal teria um componente psicológico indispensável (HUSSERL, 2003, p. 83).

Talvez não seja incorreto pensar que o problema de Husserl não seja tanto o de psicologizar a matemática (embora esta tarefa seja o preço que o filósofo tem de pagar pela racionalidade almejada), mas de escapar do vazio semântico e da pura sintaxe ao encontrar um denominador comum capaz de unificar as ideias de multiplicidade presente no tratamento das equações aritméticas. Uma vez que o conceito de número é ele mesmo uma forma de representação de uma unidade, Husserl acredita ser possível justificar tal multiplicidade ante capacidades psico-lógicas ${ }^{3}$, leis gerais que fornecem o solo comum da diversidade das operações aritméticas, ou ainda uma "constituição psicológica do conceito" (CENTRONE, 2010, p. 7).

Com efeito, a apropriação do sentido dos signos e da linguagem matemática, segundo Husserl (1994), pode evitar erros e cortar caminhos na produção desta. Esse objetivo proposto por Husserl parece ter uma gênese naquele da filosofia transcendental, mas aqui a diferença reside no fato de que a produção de uma lógica formal deve fazer parte do processo teleológico dos signos da matemática e não somente como um conjunto demonstrativo de categorias indiferentes às operações aritméticas (HUSSERL, 1994, p. 50).

Evidentemente, compondo o que será compreendido pelo próprio Husserl como um caminho para chegada de uma filosofia transcendental, há uma clara distinção entre objetos reais e objetos ideais. Isto é, não devemos entender, segundo os caminhos deixados por Kant, que as estruturas a priori sejam apenas um modo de desdobramento do empírico, ou que este seja o resultado bem-acabado de desenvolvimento daquelas. A matemática, para Husserl, não configura um tipo de ciência platônica, uma vez que elas são ideias (no sentido psico-lógico) e a produção desse sentido não é uma verificação de uma auto-evidência racional, mas de um trabalho intelectual ante as operações aritméticas. Por assim dizer, a distinção entre forma e conteúdo aqui é ressaltada de modo que Husserl deseja produzir uma metaciência do sentido (KUSCH, 2001, p. 57), ainda sem dar-se conta do hilemorfismo epistemológico próprio da tradição neokantiana como outra solução possível.

Doravante, todas as citações serão de livre tradução do autor.

Isto é mostrado a partir de esquemas relacionais em HUSSERL, 2003, pp. 53-54.

“Em 1887-1891, a origem da aritmética foi descrita em termos de gênese psicológica. Após cinquenta anos de meditação, a origem da geometria repete o mesmo projeto sob o espectro de uma história fenomenológica" (DERRIDA, 1962, p. 7, grifos do original). 
O psicologismo permanece uma ferramenta de interessante alcance, porquanto justifica a aparição do sentido ante a cegueira dos sinais da sintaxe matemática, uma intencionalidade subjacente à ordenação de operações matemáticas que são orientadas a partir de pressupostos elucidados na figura do indivíduo psicológico que filosofa.

Em outras palavras, Husserl buscava uma metaciência que não é capaz de confinar-se a um estudo sintático de teorias, mas também é obrigada a praticar a semântica. As categorias semânticas pertencem ao estudo da essência ideal da teoria como tal (KUSCH, 2001, p. 62).

Contudo, em trabalhos posteriores de Husserl, para além da refutação do formalismo de Frege, para o qual o filósofo alemão utilizara a objeção psico-lógica, o fenomenólogo teve de ser capaz de distinguir, de uma vez por todas, como o procedimento de justificação não se baseia em leis da psicologia e nem sequer devem pressupor verdades psicológicas ${ }^{4}$. Apesar de apostar na psicologia o meio essencial de arguição do sentido do número, considerando-a como indispensável para a análise do conceito deste, Husserl ainda não fizera a distinção entre o procedimento psicológico e o procedimento transcendental. O filósofo alemão considerava, neste momento, que

não só a psicologia é indispensável para a análise do conceito de número, mas essa análise também pertence à psicologia. [...] A compreensão dos primeiros e mais simples modos de composição das representações é a chave para a compreensão dos níveis mais elevados dos embaraços com os quais nossa consciência opera constantemente com formações contínuas e fixas (HUSSERL, 2003, p. 311, grifos do original).

Por esta razão, o sentido do número ficara perigosamente ligado a uma multiplicidade que não possui garantia alguma de produzir, a partir de um procedimento dogmático, as leis gerais da aritmética. Kant parece emergir como uma influência fundamental a respeito deste problema ${ }^{5}$. Já nos Paralogismos da razão pura (KANT, 2001, A342/B400), Kant distinguiu a unidade do eu penso das intuições internas do tempo. Enquanto as primeiras são produto de uma ideia transcendental, isto é, que não tem correspondência com as evidências do mundo sensível, a segunda é o aparecimento das intuições imediatas da faculdade sensível do eu empírico. Isto é, Kant torna clara e distinta a diferença entre a dupla consciência do eu e a existência de um duplo eu. Naturalmente, Husserl toma o primeiro caminho, diferenciando o método dedutivo da filosofia como pressuposto de uma filosofia da mente ou de uma filosofia das faculdades de uma lógica humana.

Temos, portanto, uma maneira renovada de produzir a semântica do objeto matemático que subjaz na figura de um eu indeterminado e anterior à aparição dos objetos da matemática. As suspeitas a respeito da cegueira semântica dos signos da linguagem matemática são mantidas. Observa-se também, juntamente à crescente insuficiência do psicologismo, uma impossibilidade nascente no projeto husserliano: seu fundacionismo não convence ao derivar a complexidade dos números não-cardinais ante as formas simples da unidade formada a partir da multiplicidade das unidades numéricas de modo satisfatório. As explicações dadas por Husserl (2003) parecem insuficientes, pois apenas reafirmam um fundacionismo ingênuo, indicando na gênese dos números irracionais, negativos, complexos e imaginários uma derivação da simplicidade de operações originárias (HUSSERL, 2003, p. 342). Parece configurar, inclusive, um reducionismo rudimentar e talvez incorreto derivar nas leis decomponíveis da matemática dos números cardinais, isto é, dos signos que emitem o sentido da contagem e da quantidade, números que não se apresentam a partir das imediatidades

4 Temos noção do quanto isto desconsidera importantes passos de reformulação da filosofia de Husserl da qual provavelmente ignoramos muitas etapas (dos achados teóricos do fenomenólogo alemão rumo à rejeição do psicologismo), mas nossa argumentação simplesmente é mostrar brevemente como o psicologismo pode ser visto como uma maneira de reativação de um paralogismo (a correlação causal entre a dedução a priori e sua contraparte empírica) que permaneceu na filosofia transcendental como um dos princípios da filosofia crítica, isto é, a distinção entre o eu sujeito e o eu objeto.

5 Husserl (1970) irá opor-se ao construtivismo regressivo de Kant. A estética transcendental para Husserl não é um produto de puras faculdades sensíveis, mas resultado de uma vivência intencional e composta de um estofo muito distinto daquele encontrado na introdução ao sistema kantiano (HUSSERL, 1970, p.94). 
da intuição de tempo e espaço. Husserl parece inverter a teoria clássica dos conjuntos dos números totais. Tudo se passa como se na exposição husserliana os números complexos estivessem fundados nos números reais, por sua vez, firmados no conjunto dos números racionais, seguido dos números inteiros e, por último, como o princípio elementar que dá origem a todos os outros, os números naturais.

Diante deste problema, haveria duas saídas: ou conferir procedimentos auxiliares para dar conta da complexidade do objeto matemático, o que poderia produzir gêneses múltiplas e o aparecimento do relativismo, para o qual Husserl jamais quis retroceder, ou atribuir uma diferença, de uma vez por todas, entre o objeto Eu e o operador de conceitos como o sujeito universal. Evidentemente, ele opta pelo segundo caminho, uma vez que embora os caminhos da obra husserliana sejam muitos, o fenomenólogo possui uma insistência clara: a semântica que é produzida pelo método husserliano é sempre um resultado acessível e único. Não por acaso, ele se opôs largamente à teoria das classes de Schröder na qual o conteúdo dos conceitos numéricos é inacessível (KUNSCH, 2001, p. 148).

Do psicologismo à fenomenologia transcendental, realizaremos outro salto necessário na extensa filosofia husserliana até chegar à exposição derridiana contida na Introdução à Origem da geometria. Este salto consiste no abandono de uma fenomenologia estática (fundação e o problema do acesso ao significado de um noema) à passagem para uma fenomenologia genética (que aparece mediante duras críticas de Husserl à ilusão a priori da filosofia crítica).

Correndo o risco de simplificar enormemente a fenomenologia estática, este empreendimento da filosofia husserliana conserva a necessidade de pensar conceitos primitivos que tornam possíveis a associação teórica, isto é, o estado de coisas do sujeito em relação ao objeto e buscar leis que regem a verdade das formações a partir destes conceitos. Este objetivo, presente desde a Filosofia da aritmética, tem a necessidade de diferenciar as "formações lógicas enquanto unidades ideais e as vivências psíquicas por meio das quais essas formações nos são dadas" (OLIVEIRA, 2006, p. 37, grifos do original). Daí que tratar positivamente destas formações lógicas, diferenciando-as da psicologia, tornou-se o mote de uma fenomenologia transcendental ${ }^{6}$. Mesmo assim, essa diferenciação entre fenomenologia estática e genética pode parecer, em um primeiro momento, simplório, uma vez que como nos lembra Steinbock $(1998)^{7}$, a busca por conceitos primitivos já é um tipo de fenomenologia genética.

Contudo, o aparecimento da fenomenologia histórica e da gênese do ego transcendental irá consolidarse como um nível de profundidade maior do que aquele encontrado na fenomenologia estática. Esta seria um nível mais abstrato da constituição, enquanto o esforço genético pôde ser entendido como um nível mais concreto dos processos generativos do eu. Isto é, ambos são métodos da constituição do sentido, em seus respectivos aprofundamentos ${ }^{8}$.

Depois de um longo caminho chegamos finalmente em como podemos pensar a matemática no interior dos processos da gênese constitutiva, terreno no qual Derrida inicia sua exposição acerca da gênese da geometria. Tomamos dois textos específicos para uma breve discussão deste problema, na filosofia de Husserl. São dois textos que nomeiam a si mesmos como a busca pela gênese de uma história (não empírica) da subjetividade e que parecem colocar a matemática como pano de fundo de uma discursividade que, ao ser historicizada, fornece condições à filosofia de pensar o percurso da auto-apresentação da gênese constitutiva e das estruturas fundamentais do surgimento de um sujeito genérico. Um deles parece rejeitar a matemática

6 "A reflexão transcendental enquanto fenomenologia transcendental é pesquisa transcendental (e não psíquica) da consciência" (OLIVEIRA, 2006, p. 39).

$7 \quad$ Para mais detalhes, Cf. STEINBOCK, 1998.

8 Arriscamos, no entanto, contra Steinbock (1998), de que mesmo que do ponto de vista de uma sistematização do pensamento husserliano, as diferenças entre fenomenologia estática e genética não sejam compostas a partir de um dualismo metodológico, mas de níveis de clarificação de um mesmo método, não podemos deixar de notar as aproximações de Husserl (cf. HUSSERL, 2001, p. 9) do idealismo alemão, nas figuras de Fichte e Hegel, ao criticar o propósito da filosofia crítica e encontrar na relação do pensamento consigo mesmo a chave para a compreensão da empresa filosófica, independente da não-filosofia. Afinal, a passagem da dedução metafísica à dedução transcendental na Analítica transcendental (KANT, 2001, A 70/B 95, B 106) é composta pelo abandono de uma Lógica do pensamento (a relação do sujeito consigo mesmo) e pelo o aparecimento de uma Lógica relacional e proposicional intimamente dependente do predicado que o sujeito atribui ao seu objeto, mediada pelo juízo. 
como uma derivação imprópria do sentido fenomenológico da consciência transcendental, enquanto o segundo texto é uma tentativa de conciliação do formalismo da matemática e da semântica.

Vimos, acima, que a aparição do sujeito genérico, em Husserl, se deu a partir da crítica ao formalismo de Schröder e de que a aparição de um ego universal seria um caminho traçado a partir do psicologismo e da busca pelo caráter elementar dos números das operações algébricas. Imediatamente, vimos, de forma muito breve, como o psicologismo coloca em risco o projeto de pensar uma filosofia do sujeito genérico, por ser incapaz de livrar-se do problema do relativismo. Daí, a busca de Husserl pela distinção entre sujeito e objeto, nos Paralogismos da razão pura de Kant, para dar conta do problema da universalidade do ego transcendental.

Em primeiro lugar, nas Análises das sínteses passivas, Husserl (2001) procura construir uma crítica ao ideal de uma ontologia matemática pura, a ontologia de um objeto em si (uma tese anti-platônica que irá ser levada ao longo de todo seu projeto filosófico). Em um primeiro momento, dirá Husserl (2001) que a matemática poderia ser vista como uma forma melhor acabada da validade transcendental, como se fosse possível, a partir de uma exposição axiomática, identificar a auto-geração do pensamento em si mesmo. No entanto, o aparecimento do caráter intuitivo (não-matemático) opera de tal modo a fornecer à consciência dados sensíveis, uma hilética, por assim dizer, que torna impossível a aparição de um objeto puro (HUSSERL, 2001, p. 311). Isto é, um processo de aparecimento de um em-si que é determinado de antemão e depende da estrutura intencional que o percebe. A partir daí, a matemática passa a ser uma forma abstrata de acesso ao sentido, porquanto a matemática ignora a correlação necessária, e oculta, existente no processo de explicitação do sentido. Tendo a discussão do correlacionismo posta pela fenomenologia, Husserl (2001) realiza uma distinção fundamental entre uma verdade matemática e uma verdade experiencial, uma vez que as provas matemáticas não fazem parte do caráter geminado essencial das intuições categoriais (do entrelaçamento do objeto com o seu sentido), mas formas objetivas de demonstração axiomáticas, incapazes de apreender seu próprio significado. Muitas vezes, o próprio Husserl (2001) se utiliza de uma gramática depreciativa para referir-se à matemática, como se se tratasse de um tipo de conhecimento inapto a engendrar ele mesmo um processo de aparecimento da novidade do sentido9. Assim, a exatidão da matemática é vista como totalmente inapropriada à ciência fenomenológica ${ }^{10}$, na qual o princípio do inacabamento tem de fazer parte do fundamento e da gênese das estruturas noemáticas.

Sendo assim, a ontologia matemática é apenas um resíduo de um fundamento muito mais rico do que aquele, uma vez que a natureza objetiva e sua matematização dão conta apenas de explicitar o sentido de um sujeito finito, aquele que nasce a partir das ciências da Natureza (HUSSERL, 2001, p. 544). Portanto, uma rejeição dupla do platonismo: tanto porque rejeita a produção de sentidos reais (uma vez que o sentido é de natureza transcendental) e segundo porque rejeita que os sentidos ideais possam ser explicitados por números. Esta tentativa de fornecer uma crítica derradeira ao formalismo da matemática parece ser o distanciamento definitivo de Husserl da pretensão de encontrar alguma pista do aparecimento de um sujeito genérico nos pressupostos indemonstrados da matemática. Contudo, em uma de suas últimas obras, Husserl é capaz de reconciliar duas pretensões contidas ao longo de sua extensa empreitada filosófica: de um lado, uma semântica universal e do outro lado, a crítica da inacessibilidade do sentido. A mediação entre o formalismo e a semântica transcendental é feita por meio de uma teleologia forte, na qual o sentido do pensamento ocidental desemboca necessariamente em uma filosofia fenomenológica.

A conciliação é bem percebida ao longo de uma reaproximação da história da matemática, na qual esta irá ser tomada como uma plataforma para atingir o princípio dos princípios, ou ainda, uma metaciência do sentido. Husserl (1970) será capaz de colocar o formalismo ante uma ordenação que põe os enunciados da

O que é apresentado, por exemplo, de forma positiva na percepção comum, na captação de elementos sensíveis e na articulação desses elementos com novidades do campo percebido. Sobretudo isto é percebido nas breves menções à consciência do tempo, nos processos de retenção e propensão de sentido (cf. HUSSERL, 2001, p. 567).

10 Cf. também a constante aproximação feita por HUSSERL (1970, p. 3-4), entre as ciências exatas da natureza (rivais da experiência fenomenológica) e da matemática. 
matemática platônica e da geometria euclidiana como constitutivas do sentido histórico da fenomenologia transcendental ${ }^{11}$.

Com efeito, na ordenação dos conceitos, Husserl (1970) nos mostra que a originalidade da matemática de Galileu é a pretensão de uma ciência racional inclusiva, capaz de abrir um caminho para uma ciência matemática do múltiplo (Mannigfaltigkeit).

Segundo Derrida (1962):

Se, na Krisis..., um lugar muito importante é reservado para Galileu e sua revolução, que Husserl coloca na origem do perigo do espírito moderno, aqui a exigência radical é a de que a sedimentação sobre a qual se fundamenta a realização de uma matemática infinita da natureza seja derrotada. É a ingenuidade galileana que, na sua genialidade mesma, deve-se reduzir para libertar a questão para a origem da geometria. (DERRIDA, 1962, p. 16-17)

Talvez, e de forma mais radical, o que a reconstrução do pensamento da física de Galileu nos mostra é a impossibilidade de desvio da intuição. Há aqui a produção de um fundacionismo muito distinto daquele encontrado nos Princípios da aritmética, embora guardem muitas similaridades na sua aposta. Galileu é para Husserl (1970) a possibilidade de fundação da ciência pura da matemática em intuições espaciais e temporais. Ao contrário do que vimos na primeira obra de Husserl, na qual a aritmética pode ser decomposta em elementos originários, o caminho da fundamentação da matemática se dá pelo reconhecimento de uma geometria intuitiva (HUSSERL, 1970, p. 26) e da investigação das formas puras do espaço e do tempo. Ou melhor, que a matemática encontra o seu fundamento na física Galilaica, uma vez que a matematização da natureza apresentada em Galileu guarda muito mais similaridades com o fundamento apodítico das ciências em geral, o mundo da vida (Lebenswelt), do que a matemática platônica e o uso de uma matemática dos símbolos.

Finalmente, esta maneira de compreensão das realidades intuitivas, embora original e seminal para a mudança do sentido da ciência, em sua totalidade, é insuficiente, uma vez que as formas puras da geometria, distanciadas do mundo, são apenas discursos objetivados de investigação do real. O sentido da exatidão das medidas matemáticas, portanto, só podem ser atingidos como fim da ciência da matematização da natureza desde que o filósofo permaneça preso na lógica própria de uma ciência particular. O que Galileu, segundo Husserl (1970), deixa de lado é não só a forma do espaço em geral, a duração da percepção, o movimento, as deformações perceptivas ${ }^{12}$, como também o processo de cofundação das formas puras em um modo compartilhado de sentido.

O filósofo tem de ser capaz de perceber o sentido da indução intuitiva de um mundo dado na experiência cotidiana. Por outro lado,

Físicos matemáticos [...] no interior da esfera aritmética do espaço-tempo, ou, ao mesmo tempo, na mathesis universalis formalizada, tratam as fórmulas matemático-físicas que lhes são trazidas como estruturas puras especiais da matemática formal, mantendo naturalmente invariantes as constantes que aparecem neles como elementos de leis funcionais de natureza factual (HUSSERL, 1970, p. 47).

E é neste sentido que o filósofo, ao temporalizar a matematização das estruturas espaciais, situando um conjunto fixo de pressupostos ante a sucessividade e retenção própria de um sistema de ideias, não precisa relegar a ciência matemática pura ao esquecimento, mas dispô-la como uma parte de uma trama total, na

11 Isto é mostrado com detalhes a partir do $\$ 8$ da Crises das ciências europeias e a fenomenologia transcendental.

12 Cf. DERRIDA, 1962, p.29, sobre a relação entre a alucinação e verdade, como também as análises de Merleau-Ponty (1976, p. 12) da ilusão de Müller-Lyer e dos processos de despersonalização do esquizofrênico (MERLEAU-PONTY, 1976, p. 395), como caminhos importantes para uma filosofia transcendental do corpo próprio. 
qual o sentido do fundamento deve ser desvelado pelas incongruências internas da exposição dos próprios pressupostos de um sistema discursivo.

O sistema matemático da natureza deve ser incluído no sistema total - mas, como parte de um sistema, o primeiro não pode ser auto-suficiente. Não se pode deixar a física aos físicos como se fosse verdadeiramente um sistema completo e depois confiar a especialistas psicológicos a tarefa de desenvolver um sistema racional próprio do braço psicológico do dualismo. (HUSSERL, 1970, p. 64)

Melhor dizendo, "É a própria história que explodiu na fenomenologia e abre-se um novo espaço de interrogação, o que será difícil de manter dentro dos limites regionais prescritos [pelas ciências particulares] desde sempre" (DERRIDA, 1962, p. 8).

O número, a magnitude, o contínuo, as formas geométricas são modos necessários da idealização de um mundo de sentido antepredicativo. É fazer das maneiras distintas de aparecimento (Erscheinungsweisen) da idealidade de um mundo pré-científico o objeto de uma filosofia fenomenológica.

É com base na temporalização do fenômeno da espacialidade da geometria, como uma ciência do sentido das formas, que apresentaremos a exposição de Derrida (1962) da tradução feita da Origem à geometria de Husserl. Pretendemos mostrar que há a subscrição de grande parte das teses husserlianas acerca da necessidade de uma filosofia não empírica do tempo, já que

A historicidade dos objetos ideais, isto é, a origem e a tradição [...] obedecem a regras incomuns, que não são nem as concatenações facciosas da história empírica, nem as de um enriquecimento ideal e ahistórico (DERRIDA, 1962, pp. 4-5, grifos do original).

Pretendemos mostrar também que a reconstrução de Derrida é feita também de suplementações que subvertem o sentido da letra de Husserl e a finalidade do método fenomenológico.

\section{Derrida e a apresentação da Origem da geometria}

O texto de Husserl apresentado por Derrida (1962) é restrito ao universo da matemática, ao contrário do que encontramos na Crise das ciências europeias e a fenomenologia transcendental, na qual encontramos uma multiplicidade de disciplinas atravessada por um exame geral do pensamento e da filosofia ocidental. Contudo, a forma da argumentação, segundo Derrida (1962), não se diferencia tanto assim entre a Crise... e a Origem da geometria tão somente se trata, nos dois casos, da apresentação dos objetos ideias da ciência, cujo caso da geometria é apenas um dentre outros vários (DERRIDA, 1962, p. 3).

Corroborando a letra de Husserl da Crise..., Derrida identificará a reativação de um sentido originário a partir das unidades ideais da aritmética e sugerirá o retorno às estruturas de uma subjetividade concreta (DERRIDA, 1962, p. 6). De maneira mais clara, Derrida (1962, p. 25) afirmará que

Uma vez que toda objeção ideal é produzida pelo ato de uma consciência concreta, o único ponto de partida para uma fenomenologia transcendental, toda objeção ideal tem uma história que sempre se anuncia já nela, mesmo que não conheçamos seu conteúdo determinado.

Assim sendo, Derrida (1962) nos descreve um processo, a esta altura conhecido, um procedimento que procura produzir a gênese da geometria acobertada em uma proto-geometria. No entanto, Derrida põe de maneira bem mais clara as dificuldades enfrentadas por Husserl no caminho de produção de uma gênese da geometria, uma vez que a possibilidade da origem põe em perigo a segura distinção entre o $a$ priori e o 
empírico, presentes na fenomenologia estática. De que maneira Husserl pode pensar em uma filosofia que é, de certo modo, devedora das reflexões de Kant, mas sem se deixar levar pelas ilusões do apriorismo? Como pensar em uma gênese histórica da geometria sem se deixar levar pela necessidade de produção de uma forma ambígua entre o sujeito genérico e a história da subjetividade concreta? ${ }^{13}$.

É preciso, pois, enfrentar o problema da história como fundamento das crenças e dos projetos comunitários. Igualmente, é preciso conceber a possibilidade de articulação entre a aparente diferença dos enunciados ante a síntese primordial do sujeito. Isto é, como as cosmo-visões (Weltanschannung) de sujeitos múltiplos - assim como a multiplicidade das unidades numéricas - podem ser reduzidas à figura de um eu transcendental? Afinal de contas, a fenomenologia genética seria uma tentativa de Husserl

[...] de conciliar o requisito estruturalista que leva à descrição compreensiva de uma totalidade, de uma forma ou de uma função organizada de acordo com uma legalidade interna em que os elementos têm significado somente em solidariedade de sua correlação ou em sua oposição, com a exigência genética, ou seja, a solicitação da origem e do fundamento da estrutura (DERRIDA, 1967, p. 233, grifos do original).

Segundo Derrida (1962), esta convivência entre a história concreta da formação dos conceitos, dos nomes próprios e a história transcendental, isto é, o sentido do pensamento na sua auto-explicitação, são dois princípios articuláveis, uma vez que é exatamente porque as produções ideais são autônomas, ou ainda, multiplicidades incomunicáveis, que é preciso produzir uma fluidez entre conceitos aparentemente inconciliáveis. Isso porque, "[e]sta referência ao ato de produção está inscrita na sua formação mesma, mas pode passar despercebida por causa da autonomia das formações ideais" (DERRIDA, 1962, p. 44). Husserl é capaz não só de ordenar estas multiplicidades ante o objetivo de um sentido da história do pensamento, retirando os discursos de uma autonomia epistemológica, como ao final, produzir uma intersubjetividade transcendental ${ }^{14}$. O tom de aproximação entre Hegel e Husserl permanece como uma atmosfera no texto de Derrida, uma vez que, segundo o filósofo francês, não há uma história natural em Husserl pelos mesmos motivos que encontramos em Hegel. Ou ainda, a filosofia da história de um tempo não empírico que é contada na Fenomenologia do espírito é capaz de responder algumas questões do método fenomenológico.

Uma das primeiras suplementações que Derrida (1962) faz ao trabalho de Husserl é exatamente a objeção ao estado de sucesso do método fenomenológico. Esta nota dará a primeira forma às críticas ao projeto moderno da filosofia de Husserl. Uma delas é a breve análise de Derrida (1962) sobre a resistência da linguagem à unidade proposta por Husserl, como se fosse possível à linguagem oferecer um limite à tentativa de produzir um monismo semântico.

É, portanto, na medida em que não é "natural" que, paradoxalmente, a linguagem oferece a resistência mais perigosa à redução fenomenológica; ao discurso transcendental restará, irredutivelmente, ficar apagado por um certo mundanismo ambíguo (DERRIDA, 1962, p.60).

A linguagem aparece aqui por duas razões: a primeira delas é por conta das exigências próprias à execução do método fenomenológico, uma vez que o reconhecimento da primeira redução é tornar a multiplicidades dos enunciados auto-consciente do seu fundamento (Lebenswelt) e, em segundo lugar, de certa forma decorrente da primeira razão, porque a matemática, ela mesma, não deixa de ser compreendida como uma linguagem mais universal do que aquela da vida cotidiana, uma vez que é capaz de produzir um estado de acordo intersubjetivo, um sentido unívoco, ante as multiplicidades de uma comunidade falante. Daí porque

13 Sobre o estrabismo da fenomenologia Husserliana, cf. Merleau-Ponty (1995, p. 103-104). Veremos adiante que Derrida (1962) não assumirá nem a distinção clássica do hilemorfismo epistemológico de Kant, tampouco a filosofia ambígua de Merleau-Ponty.

14 Embora "Fenomenologicamente, o nós [da subjetividade] transcendental não é senão o eu transcendental" (DERRIDA, 1962, p. 50, grifos do original). 
"A geometria é, de fato, a ciência do que é absolutamente objetivo, a espacialidade, nos objetos que a Terra, nosso lugar-comum, podem fornecer indefinidamente, como um terreno comum de contato com outros homens" (DERRIDA, 1962, p. 78-79, grifo do original). Na verdade, o tom da crítica que Derrida (1962) faz a Husserl é posto em termos mais simples como a possibilidade de fundação de uma linguagem universal, já que "Na sua essência, o problema da origem da geometria faz aparecer a constituição da intersubjetividade e da origem da fenomenologia da linguagem" (DERRIDA, 1962, p. 73).

Mas, segundo Derrida (1962), não seria um tipo qualquer de fenomenologia da linguagem. Como ressaltamos acima, a semântica produzida pelo método husserliano produz um sentido necessariamente acessível a todos. Por isso, a fenomenologia da linguagem em jogo no projeto husserliano diz respeito à possibilidade de que todo sentido seja nomeável, isto é, experimentado como uma linguagem. Por outro lado,

A não-comunicação e o mal-entendido não são o horizonte mesmo da cultura e da linguagem? Sem dúvida, o mal-entendido é sempre um horizonte factual e o índice do pólo infinito da boa inteligência. Mas, embora esta sempre se anuncie para que a linguagem possa começar, a finitude não seria o essencial que nunca pode ser excedido radicalmente? (DERRIDA, 1962, p. 77)

Essa resistência de Derrida em assumir o monólogo de Husserl se dá pelo fato de que uma linguagem não pode existir como um objeto absoluto, ou como um predicado inamovível.

Ora, se o propósito do método transcendental coloca, sem grandes problemas, a possibilidade de um dissenso, ou do não-sentido, o resultado do método fenomenológico tem a esperança de colocar esse elemento extrínseco da história do pensamento em um percurso no qual o sentido perdido na efetivação concreta do tempo empírico seja retomado em uma história transcendental.

\section{A temporalização da geometria}

Mas afinal de contas, como é possível a passagem dos enunciados geométricos, como linguagem formal aos enunciados de fala da vida cotidiana? São possíveis, pelo menos, por dois motivos: o primeiro deles é certo ranço da filosofia de Kant, na qual a identidade lógica da percepção, encontrada na estética transcendental, é realizada pela primazia do tempo ante o espaço. Um objeto dado na multiplicidade do espaço deve ser posto em termos de uma síntese a qual o próprio objeto não pode nos fornecer - sendo assim, portanto, uma das primeiras formas do juízo sintético a priori. Mas as demonstrações de Derrida da filosofia de Husserl colocam o tempo em uma hierarquia não devidamente contemplada nas formas puras da faculdade sensível da filosofia crítica: a de realizar uma articulação e um ponto de comunicação entre a estética e a analítica, reconhecida por Kant meramente de um ponto de vista lógico-formal, na dialética. Esta omnitemporalidade é um artifício que conserva a distinção entre a formatação do pensamento e de seus aparecimentos na dispersão da história dos fatos. Portanto:

[...] é na medida em que os sinais podem ser imediatamente perceptíveis por todos na sua corporeidade; é na medida em que os corpos e formas corporais estão sempre em um horizonte de intersubjetividade que o significado pode ser registrado e colocado em comunidade. A exterioridade corporal não é o sinal como tal, sem dúvida, mas, em um sentido que deve ser esclarecido, ele é indispensável" (DERRIDA, 1962, p. 93, grifos do original).

A proto-geometria, condição de enunciação dos conceitos geométricos, deriva de uma intersubjetividade já estabelecida, cabendo ao filósofo explicitar aquilo que não é imediato ao pensamento. E é por esta razão que Derrida (1962) explicitará a diferença, em Husserl, entre o corpo (Körper, corps) e o corpo vivo (Leib, chair). 
Embora as palavras, Körper e Leib, corpo e carne, serem numericamente, de fato, um e o mesmo ser, seus sentidos são definitivamente heterogêneos e nada pode chegar a ele por aquele. O esquecimento da própria verdade nunca será, senão a falência de um ato e a abdicação de uma responsabilidade, uma falha mais do que uma derrota. Ele só pode ser convocado pessoalmente de uma história intencional (DERRIDA, 1962, p. 98, grifos do original).

Por isso, a filosofia de Husserl, para Derrida (1962), parece ser nem tanto uma filosofia do sentido constituído ou de uma subjetividade suprassensível; não parece se tratar aqui de produção de uma verdade transcendental, mas de sua verificação; significa dizer melhor, através da filosofia, aquilo que já se encontra dito nas formas da vida cotidiana.

A distinção entre o corpo vivo e o corpo da física, pode parecer muito próximo das colocações hegelianas nas quais "[...] a liberdade do ser-para-si só se comprova na facilidade de relacionar-se com todas as coisas e de conservar-se nessa variedade multiforme" (HEGEL, 2014, p. 207). Assim sendo, as figuras do espírito realizam o ponto de convergência daquilo que permanecera como uma multiplicidade dispersa na natureza.

Na verdade, a aproximação entre Husserl e Hegel por Derrida é a de aclarar as dificuldades enfrentadas por Husserl e de iluminar os problemas da produção de uma filosofia da forma da infinitude, sem permanecer sob o jugo dos juízos regulativos, tampouco da metafísica da história encontrada em Hegel (DERRIDA, 1962, p. 105). Por isso mesmo, o fantasma da finitude ronda o pensamento husserliano. Ele chega a ser diagnosticado por Foucault $(2007)^{15}$ como uma reativação de uma má ambiguidade que é encontrada no pensamento filosófico pós-Kant. Para Derrida (1962), ao contrário, Husserl não pode ser entendido como um filósofo da finitude, mesmo profundamente atravessado pelo problema da intersubjetividade e da história. Com efeito, "[o] campo de interrogação não tem limites, uma vez que abrange a totalidade infinita do ser e do significado" (DERRIDA, 1962, p. 111).

Assim, mesmo que a reflexão do a priori histórico se alimente da historicidade empírica, ele permanece como a condição de toda linguagem (geométrica, artística, falada, etc). Ao mesmo tempo, o a priori não poderia operar na intersubjetividade uma historicidade da antecipação, uma vez que Husserl "[...] nunca pensou em prever, com alguma dedução eidética, todos os fatos, todas as possibilidades particulares que devem se adequar a estes apriori da historicidade universal." (DERRIDA, 1962, p. 117). Daí o reconhecimento de Derrida (1962), em Husserl, de um transcendental distinto daquele que encontramos em Kant. Enquanto este é uma ciência dedutiva de um procedimento dogmático, aquele é a ciência da invariância de uma diferenciação interna e dinâmica.

Com efeito, as críticas de Husserl ao projeto transcendental clássico, para Derrida (1962) permanecem muito próximas de Hegel para quem a filosofia crítica é a "[...] forma, única e imóvel” e por isso mesmo "adaptada pelo sujeito sabedor aos dados presentes", no qual "o material [predicado] é mergulhado de fora nesse elemento tranquilo [sujeito]” (HEGEL, 2014, p. 31). De forma análoga,

na matemática, um postulado é uma proposição prática, que apenas contém a síntese pela qual damos a nós próprios um objeto e produzimos o seu conceito; assim, por exemplo, com uma linha dada, a partir de um ponto dado, descrevemos um círculo sobre uma superfície. E semelhante proposição não pode ser demonstrada, porque o processo que ela exige é, precisamente, aquele pelo qual produzimos, antes de mais, o conceito de tal figura. Sendo assim, temos o mesmo direito de postular os princípios da modalidade, porque não alargam o conceito de coisas em geral, somente indicam a maneira como o conceito está ligado em geral à faculdade de conhecer (KANT, 2001, A 235).

Ou seja, a pureza e a exatidão da matemática, contida na apresentação da dedução metafísica, em oposição à dedução transcendental (que supõe, portanto, uma categoria de relação não encontrada na primeira), é a

15 Cf. Foucault (2007, p. 268, 348 e 350). 
forma de um juízo necessário e que, por esse motivo, não pode ser demonstrado e encontra sua validade na sua relação consigo mesmo. Existe em Kant uma dualidade metodológica, por assim dizer, no caminho da dedução dos princípios dos princípios. No primeiro caso [dedução metafísica], temos as categorias que evitam a ligação com aquilo que lhe é exterior, para conservar a sua pureza, sendo o modelo da ciência em geral e no segundo caso [dedução transcendental], uma categoria de relação, que amparado no primeiro princípio, põe-se a descrever a possibilidade de produção de um juízo necessário a respeito do mundo.

O que Hegel (2014) dirá é que o segundo passo (a dedução transcendental) não concerne ao conteúdo próprio da relação entre sujeito e predicado, mas só é possível através da mediação de um terceiro termo: o juízo.

Assim não é a natureza do triângulo retângulo que se decompõe tal como é representada na construção necessária à demonstração do teorema que exprime sua relação; todo [o processo de] produzir o resultado é um caminho e um meio do conhecimento (HEGEL, 2014, p. 47).

O conhecer matemático é falso, porquanto prossegue em uma linha de igualdade consigo mesmo. "O morto não se move" dirá Hegel (2014) sobre a natureza axiomática dos princípios metafísicos kantianos, uma vez que este formalismo considera apenas grandezas, deixando de fora o infinito que escapa à sua determinação (HEGEL, 2014, p. 49). Ao que parece, a temporalização da geometria em Husserl é uma adesão às críticas hegelianas, sem se deixar tomar pelo abandono das pretensões transcendentais.

A matemática volta a ser, alimentada pelas críticas de Hegel, em Husserl, um princípio modelo, uma vez que ela é a disciplina capaz de se aproximar mais verdadeiramente dos modos intersubjetivos da constituição do mundo da vida. Uma vez que a matematização do espaço é aquilo que dá conta de produzir uma ciência de uma categoria presente no trato da vida comunal, uma forma ainda não realizada do nós da intersubjetividade transcendental. Por isso mesmo, com o reconhecimento de que a geometria não é mais composta de um conjunto de axiomas indemonstráveis, Husserl é capaz de contar a história do seu aparecimento. Da matemática platônica, às formas puras do número, até o aparecimento da física moderna de Galileu. Aqui, o encontro do tempo com o espaço é entendido como o labor indefinido de um sentido que apreende a si mesmo indefinidamente e como um princípio de uma eidética.

\section{Suplementos de Derrida à filosofia de Husserl}

Derrida (1962) já demonstrou resistências ao longo de sua apresentação, quanto à possibilidade mesma de uma filosofia transcendental que reduzisse o sentido da linguagem em uma produção de um eu unívoco. Por outro lado, Husserl (1970) já havia caracterizado o método fenomenológico a partir de dois passos: o primeiro seria a redução de todo conteúdo formal e objetivo à esfera da intersubjetividade e do mundo da vida. Contudo, a insuficiência deste primeiro passo coloca Husserl diante da tarefa de uma segunda redução. Esta redução da redução implica não somente reconhecer o fundo comum das produções formais, mas a consciência transcendental deve possibilitar "[...] um esclarecimento final sobre o seu significado" (HUSSERL, 1970, p. 176). A partir deste momento, os caminhos entre Husserl e Derrida se separam e este pode subverter a letra de Husserl, produzindo uma suplementação à fenomenologia.

A subversão da qual falamos é um longo debate que surgiu na tradição da filosofia francesa diante do problema da gênese e da estrutura. O primeiro corresponde ao esforço husserliano de uma orientação teleológica dos sentidos dispersos da linguagem múltipla da história e a segunda da inteira diferença e da conservação das multiplicidades sem as figuras mediadoras da unidade.

Em um relato posterior sobre esta obra específica, Derrida (1987) revela que o seu objetivo à introdução da Origem da geometria era apresentar os pontos de fuga de uma linguagem que não poderia ser entendida inteiramente como a épochè e indicar a falta de atenção com a qual Husserl havia pronunciado sua enunciação fenomenológica. Daí os diagnósticos dos lapsos na letra husserliana: sobre o constante risco de que uma 
linguagem não pudesse ser submetida, como acreditava Husserl, à unidade da redução fenomenológica. Uma linguagem que não pudesse ser entendida somente ante a narrativa da gênese transcendental na qual nenhum elemento compõe uma unidade sem anunciar a si mesmo de antemão.

Mais radicalmente, o que a teleologia husserliana parece indicar são consequências muito radicais. Derrida enxerga a possibilidade no método de Husserl, para além de um percurso capaz de produzir uma propedêutica definitiva do eu transcendental, o próprio cerne do pensamento a consciência de uma historicidade ${ }^{16}$. Portanto, esta

[...] teleologia que nunca deixou de fundar e animar o pensamento husserliano não pode, no entanto, ser determinada em uma linguagem filosófica sem destruição temporária dessa unidade a favor da fenomenologia. (DERRIDA, 1962, p. 168)

Finalmente, o que o texto husserliano revela, segundo Derrida (1962), a despeito das intenções do próprio autor - inclusive ante a possibilidade de recusa desta revelação - é a da indicação do fracasso de execução do método e da apresentação da redução fenomenológica como o esforço indefinido de tentativa de apropriação de um Si mesmo.

Com efeito, o fracasso do método revela a necessidade de perscrutar o sujeito genérico em afirmações nas quais ele não se anuncia. O transcendental, desta forma, é a Diferença, como uma origem absoluta, ou ainda,

[o] transcendental seria a pura certeza de um Pensamento que, não podendo esperar pelos Telos que já se anuncia, que ao avançar sobre a Origem que se reserva indefinidamente, nunca teve que aprender que sempre chegaria (DERRIDA, 1962, p. 171).

Contudo, não se trata aqui de um abandono inteiramente radical de Husserl, renunciando a própria possibilidade de um sujeito genérico. Neste sentido, as distinções propostas por Husserl acerca do empírico e do transcendental são mantidas (a origem empírica versus a origem transcendental, as estruturas empíricas versus a estrutura transcendental). Isso porque Derrida deve sempre supor que o caráter interminável do eu transcendental, como um "grau mínimo de existência em um mundo determinado" (BADIOU, 2015, p. 212), seja distinguido da ordem dos fatos e que a tarefa de torná-lo inteiramente nomeável, seja furtar-se de nomeálo inteiramente. Assim, mesmo que a Diferença apareça ao fim do texto e de modo talvez surpreendente, ela indica a possibilidade de que ela mesma possa ser entendida como uma categoria transcendental, como uma distinção da ordem dos fatos, um princípio que por ainda não se revelar como tal, o caracteriza como uma significação exemplar.

Embora não exista uma clareza sistemática da suplementação feita por Derrida, ela existe realizando o gesto de "mostração". Segundo Badiou, é uma tarefa que apresenta "[...] delicadamente o ponto de fuga, ao mesmo tempo que o deixa fugir. Vocês não podem mostrá-lo 'como' ponto de fuga, mostrá-lo morto. É isso que Derrida mais teme. Mostrar o ponto de fuga morto. Mostrar o ponto de fuga sem fuga. Vocês têm, pois, uma escritura que vai tentar ser essa mostração. Chamo isso de localização. Porque mostrar é localizar. E dizer: 'psiu, está talvez ali, cuidado!.... está talvez ali.... não o interrompa... deixe-o fugir...' (BADIOU, 2015, p. 214).

Finalmente, embora o transcendental aqui vai ser entendido contra todo o procedimento dogmático de Kant, não é surpreendente que este ainda oriente a ideia de infinito cuja natureza aproximativa se desvia sempre de uma determinação absoluta (Kant, 2001, A 432 /B 460).

16 "Dans ses implications les plus radicales, la Méthode n’est donc pas la préface neutre ou l'exercice préambulaire d'une pensée, mais la pensée elle-même dans la conscience de son historicité intégrale (DERRIDA, 1962, p. 166, grifo do original). 


\section{Considerações finais}

O presente texto se dividiu em duas partes: na primeira, procuramos mostrar como o problema da fundação da matemática aparece em Husserl, bem como o abandono ao psicologismo, sua chegada à filosofia transcendental e as exigências de uma profundidade na busca dos conceitos primitivos não contemplados pela fenomenologia estática. Husserl partira de uma ideia na qual o formalismo deveria ser combatido a partir de sua antítese, buscando fundar o sentido dos números ante a simplicidade dos elementos cardinais que compõe uma ordenação mais simples possível. Esta ordenação seria o fundamento da complexidade das equações e das operações aritméticas. Em seguida, vimos muito brevemente, como esse caminho leva Husserl muito próximo de realizar uma indução psicológica de leis gerais. Daí a apropriação do fenomenólogo da distinção encontrada na filosofia transcendental entre as faculdades sensíveis da intuição interna e a unidade pressuposta do eu transcendental.

Husserl não pôde, no entanto, desviar-se dos limites de uma filosofia dos fundamentos ante a ilusão do apriorismo kantiano e direcionou-se para uma crítica profunda dos axiomas matemáticos e da dedução metafísica dos conceitos. Por isso, o fenomenólogo encontrou-se diante da reativação de um velho problema: a possibilidade de indistinção entre o a priori e o empírico. Derrida, na sua apresentação da filosofia de Husserl encontra no risco de reativação destes problemas importantes suplementações. Estas que aparecem de forma pouco sistematizada, mas são suficientes para colocar os objetivos da filosofia transcendental em risco, uma vez que o mundo da vida (acompanhado da linguagem) poderia não ser trazido pacificamente para uma estrutura sintética capaz de unir a multiplicidade de elementos dispersos.

Procuramos mostrar que Derrida, ao tornar o fantasma da impossibilidade de efetivação da redução fenomenológica o objeto de sua investigação, deve chegar a uma conclusão possivelmente não aceita por Husserl: a de que em vez de insistirmos em um Eu transcendental, devemos tomar o fundamento da multiplicidade como a própria Diferença ${ }^{17}$. Isto é, o risco de um método que não possui finalidade e que por esta razão talvez o fundamento do pensar não seja encontrado no sentido da redução fenomenológica, mas, na verdade, o próprio pensamento seja o esforço constante da retomada de um método da síntese provisória (sempre insuficiente), ou ainda, uma unidade imaginativa prestes a se dissolver ante a riqueza da linguagem e do mundo da vida.

Não é por acaso que a matemática e a multiplicidade, acompanhado da crítica do Um, apareçam como objeto de investigação de Derrida: já em Aristóteles (1956), o Um não pode existir como predicado, mas como substância e embora o aspecto da multiplicidade das quantidades só pode ser conhecido através dos números, ou seja, a quantidade só pode ser conhecida através da diferença entre a forma do número e o conteúdo das coisas sensíveis, a quantidade ela mesma não oferece a estabilidade da substância. Por isso, a mudança da qualidade oferece um terreno mais estável do que aquela da quantidade. Essa diferença entre a forma do número e coisa sensível permanece em Husserl, mas somente até o ponto onde o filósofo alemão descobre a fenomenologia genética, capaz de bagunçar a distinção entre sujeito e objeto. Afinal, a verdade do eu transcendental não é inteiramente alheia à vida cotidiana, embora precise ser aclarada pelo eu filósofo. Derrida passa a criticar essa indistinção para garantir que a multiplicidade seja tomada enquanto tal, embora ele faça isso ao preço de uma quase reativação de um hilemorfismo entre forma e conteúdo, o qual o próprio Husserl não parecia mais conseguir sustentar.

Aqui está em jogo a tentativa de abandono do Um a partir da forma da síntese transcendental, duramente sustentada por procedimentos auxiliares na filosofia husserliana. Esta argumentação estava claramente fadada ao fracasso, uma vez que a natureza do múltiplo não poderia ser constrangida à formalização débil do Um. Em compensação, como transmitir a natureza dispersa da quantidade a partir de um conceito? A solução de Derrida se apresenta como uma manobra que parece dar início a uma maneira de filosofar distinta: usar a linguagem não só como a transmissão, mas como parte do processo de determinação conceitual. Isto significa

17 A grafia da palavra não é ainda dada a partir do neologismo derridiano, encontrado em trabalhos futuros, qual seja, a Diferança. 
que designar o conceito Diferença não é somente dar à linguagem um novo léxico para se referir a algo que a filosofia husserliana tomava como um ponto cego, mas a própria tentativa de criação de uma nova nomeação e com ela abrir um espaço para uma maneira renovada de apresentação do múltiplo enquanto tal.

\section{Referências bibliográficas}

ARISTÓTELES. Metaphysics. Trad: David Ross. London: J.M. DENT \& SONS, 1956.

BADIOU, A. Jacques Derrida (1930-2004). In: . A Aventura da filosofia francesa no século XX. Belo Horizonte: Autêntica, 2015.

CENTRONE, S. Logic and Philosophy of Mathematics in the Early Husserl. Netherlands: Springer, 2007.

DERRIDA, J. Gènese et sctuture. In: . L'écriture et la différence. Paris: Édition Seuil, 1967.

DERRIDA, J. Introduction. In: Husserl, E. Lorigine de la géométrie. Paris: Presses Universitaire de France, 1962.

DERRIDA, J. The time of a thesis: ponctuations. In: Montefiore, A. (org). Philosophy in France today. New York: Cambridge University Press, 1987.

HEGEL, G. W. F. Enciclopédia das ciências filosóficas - v. III - A ciência da lógica. São Paulo: Loyla, 1997.

HEGEL, G. W. F. Fenomenologia do espírito. São Paulo: Vozes, 2014.

HUSSERL, E. Crisis of european sciences and transcendental phenomenology. Northwestern University Press, 1970.

HUSSERL, E. Early Writings in the Philosophy of Logic and Mathematics (Husserliana: Edmund Husserl - Collected Works). Netherlands: Springer, 1994.

HUSSERL, E. Philosophy of Arithmetic: Psychological and Logical Investigationswith Supplementary Texts from 18871901. Netherlands: Springer, 2003.

KANT, I. Crítica da Razão Pura. Lisboa: Calouste Gulbenkian, 2001

KUSCH, M. Linguagem como cálculo versus linguagem como meio universal. São Leopoldo: Unisinos, 2001.

MERLEAU-PONTY, M. Phénoménologie de la perception. Paris: Gallimard, 1976.

OLIVEIRA, M. A. A semântica de E. Husserl: concepção tradicional da linguagem expressa em termos da filosofia da consciência. In: . Reviravolta linguístico-pragmática na filosofia contemporânea. São Paulo: Loyola, 2006.

STEINBOCK, A. Husserl's static and genetic phenomenology: Translator's introduction to two essays. Continental Philosophy Review, 31: 127-134, 1998. 